\title{
Higher low back and neck pain in final year Swiss health professions' students: worrying susceptibilities identified in a multi-centre comparison to the national population
}

\author{
Rebecca J. Crawford ${ }^{1 \dagger}$, Thomas Volken ${ }^{2+}$, René Schaffert ${ }^{2 *}$ (1) and Thomas Bucher ${ }^{3}$
}

\begin{abstract}
Background: Low back pain (LBP) and neck pain (NP) are of considerable socioeconomic burden. Considering the escalating demand on health services that LBP and NP have globally, they represent an arguably unsustainable drain on resources with the projected increased demand secondary to an ageing population. Identifying populations at risk for LBP and NP may inform public health prevention strategies. Health professions' (HP) students may be more susceptible due to their demographic factors and potentially risky postural demands of their education and formative clinical practice. The aim of our study was to compare self-reported LBP and NP of HP students with the general and stratified Swiss population to identify their prevalence. In addition, we compared the prevalence of LBP and NP in students studying different professions in order to identify whether susceptibilities exist.
\end{abstract}

Methods: In this cross-sectional study, self-reported LBP and NP reported by final-year HP students $(n=1848)$ were compared with the Swiss national population aged $\geq 15$ years living in private households $(n=21,597)$. Binary regression models estimated crude prevalence and prevalence adjusted for age, gender, and education. Design-based F-Tests assessed differences between students and the Swiss population.

Results: Crude, overall four-week (4W) prevalence (mean (95\% Cls)) for LBP was 61.0\% (58.4-63.5) in all HP students versus 40.0\% (39.2-40.9) in the Swiss population. Female HP students aged 21-30 years (63.3\% (60.5-66.1)) reported higher LBP than the same-aged Swiss female population with secondary (43.7\% (39.5-47.9)) or tertiary (36.6\% (30.8-42.9)) education. Crude, overall 4w prevalence for NP was 59.8\% (57.2-62.3) in all HP students versus 36.4\% (35.6-37.3) in the Swiss population. Female health professions' students aged 21-30 years reported higher NP (63.2\% (60.4-66.0)) than the same-aged Swiss female population with secondary (36.6\% (32.7-40.8)) or tertiary (35.4\% (29.6-41.8)) education. The inter-professional differences shown indicate midwifery to be most susceptible to reporting both conditions.

\footnotetext{
* Correspondence: shar@zhaw.ch

${ }^{\dagger}$ Rebecca J. Crawford and Thomas Volken contributed equally to this work.

${ }^{2}$ Institute for Health Sciences, Zurich University of Applied Sciences,

Winterthur, Switzerland

Full list of author information is available at the end of the article
}

(c) The Author(s). 2018 Open Access This article is distributed under the terms of the Creative Commons Attribution 4.0 International License (http://creativecommons.org/licenses/by/4.0/), which permits unrestricted use, distribution, and reproduction in any medium, provided you give appropriate credit to the original author(s) and the source, provide a link to the Creative Commons license, and indicate if changes were made. The Creative Commons Public Domain Dedication waiver (http://creativecommons.org/publicdomain/zero/1.0/) applies to the data made available in this article, unless otherwise stated. 
(Continued from previous page)

Conclusions: Considerably higher LBP and NP were reported by final year HP students when compared with the general and stratified Swiss population. Worrying inter-professional susceptibilities were shown and reveal the need for further explanatory studies. Measures to reduce complex health problems like LBP and NP should be introduced into curricula in order to optimize the longevity of clinical careers and to protect the future HP workforce.

Keywords: Low back pain, Neck pain, Self-reported health, Health profession, Students, Switzerland, Swiss health survey

\section{Background}

Low back pain (LBP) and neck pain (NP) are among the most prevalent and disabling diseases globally [1] impacting individuals at a personal level, and more widely, the public at large $[2,3]$. Like the rest of the world, LBP is Switzerland's most disabling disease; NP ranks third, which is one rank above its global position $[1,4]$ and may suggest relatively more NP in the Swiss population [5]. These common musculoskeletal conditions have shown the greatest growth in health spending in the last two decades $[3,6]$ with an even higher economic burden projected [7] to coincide with the world's ageing population $[2-4,8,9]$. The variety and uptake of treatments for LBP in particular have increased $[6,10]$; yet, without appreciable reduction in the problem $[1,3$, 9]. Novel, effective, and resource-efficient strategies are urgently needed to mitigate the economic, social, and personal impact of LBP and NP $[3,11,12]$. Identifying and understanding causation for populations at risk for developing these conditions is an important step toward promoting and instigating preventative and mitigating public health measures.

Both LBP and NP are common, with point and yearly prevalence (LBP/NP) around $18 / 14 \%$ and $38 / 26 \%$, respectively. However, incidence and prevalence vary considerably with the population studied and therefore mean estimates should be considered against equitable comparators [13, 14]. A systematic review showed the incidence of LBP to be highest for those aged in their twenties, and an overall increasing prevalence toward the 60-65 year age-group, with a gradual decline thereafter [13]. Worryingly in terms of sustained burden, most people who experience activity-limiting LBP have recurrence within a year [13] and are vulnerable to progression to chronicity as a considerably tenacious problem [15]. Other common risk factors for LBP include low educational status, mental health problems, job dissatisfaction, and poor workplace support [13]. For NP, there is an increased risk approaching the age-group 35-49 years, with a gradual decline thereafter [14]. The prevalence of NP is generally higher in women than men, in high-income countries, and particularly more prevalent in office-workers [4, 14]. In Switzerland, the prevalence and cost-burden of LBP and NP appear on the high-end of global estimates [5, 16], and are likely influenced by several environmental and personal factors.

Considering these known risk factors, health profession (HP) students may be vulnerable to LBP and NP as they are a predominantly young, female demographic, $[17,18]$ and who likely spend considerable time in desk-based study postures. Educational programmes for HPs in Switzerland consist of about 1800 study hours per year involving 40\% classroom teaching and $60 \%$ self-directed study [19]. Literature suggests that the prevalence of LBP and NP in students and practicing HPs appreciably exceeds mean estimates [20-27]. Furthermore, findings indicate that evidence for inter-professional susceptibilities exist [20-22]. Commencing professional careers with existing LBP or NP may threaten longevity and productivity at work, which is worrying in light of the World Health Organization identifying a mounting global HP work-force shortage [28]. This concern has also been confirmed for Switzerland where almost $20 \%$ more HPs are needed by 2025 to match projected demand [29]. In order to face the work-force challenge this presents, it will be necessary to recruit more students and also to reduce attrition from university and clinical practice that LBP and NP may contribute to.

HP students were surveyed in an overarching study to gain insights regarding their entry into the profession and to identify student competencies and factors that optimize retention in the work force. The survey comprised questions on health status, and specific questions on LBP and NP were then employed in the current study. Our first aim was to examine the prevalence of LBP and NP in HP students in comparison to the Swiss population. Our second aim was to determine whether inter-professional differences in prevalence existed, such that susceptibilities within the Swiss HP student population might be better understood and to enable targeted management. As far as we are aware, our study is the first to compare HP students' self-reported LBP and NP to the national population, and specifically to stratified peers. We deemed this national focus as essential in effectively understanding the gravity of the problem at a local level in order to provide evidence for public health and institutional changes. 


\section{Methods}

\section{Study design}

The study is a comparative, secondary analysis of a population-based cross-sectional health survey (2012) and final year health professions' student surveys (2016 and 2017) undertaken in Switzerland.

\section{Study population and data}

The Swiss Health Survey (SHS) undertaken by the Swiss Federal Statistical Office (SFSO) is a nationwide survey on health status, health service utilization, and health-related behavior. The SHS employs telephone interviews and subsequent written questionnaires; it was first conducted in 1992 and is repeated every five years. For each survey year, a multistage probability sample is drawn of the permanent resident (including foreign nationals) population in Switzerland after stratification by the three predominant language/geographic regions (German, French, and Italian). Samples include individuals' aged 15 years or older living in private households and excluding those living in institutions, i.e. hospitals, homes for the elderly, prisons, monasteries, and military barracks; only subjects conversant in either of the three languages are surveyed. Data were collected and administered by the SFSO under the regulation of the Federal Statistics Act (FSA) of 1992, which is a framework of law dedicated to federal data collection, data protection, and data security. Participants provide informed consent, which accommodates all future use of the data for research (FSA, 1992).

For our study, we obtained the most recent SHS data (2012). The respective net sample size comprised $n=$ 21,597 respondents, representing 6,838,268 subjects in the general population. Data for HP students were derived from the National Survey of Final Year HP Students (National Graduate Survey of Health Professionals from Universities of Applied Sciences; Nat-ABBE). The Nat-ABBE is a nationwide census survey of final year HP students at six universities within the three major language regions (German, French, and Italian). The Nat-ABBE is part of a nationwide collaboration of Universities of Applied Sciences (https://www.cnhw.ch/en/) to develop a competence network to counter projected shortages in the health workforce. While the main focus of the Nat-ABBE encompasses education and professional development, it also comprises several questions on health status, and health-related behavior. The Nat-ABBE employs written online questionnaires; it was first conducted in 2016 and is repeated every year. We obtained Nat-ABBE data for the years 2016 and 2017 with a respective sample size of $n=1980$. This sample was reduced to include only full-time students and students of large faculties, i.e. midwifery, nursing, nutritional sciences, occupational therapy, and physiotherapy $(n=1848)$. Excluded subjects $(n=132)$ comprised all students from Medical Radiology $(n=47)$ because this subject can only be studied in the French speaking part of Switzerland. Moreover, students of nursing and midwifery with a nursing diploma were also excluded ( $n$ $=85$ ) because they worked already in the healthcare system, they studied part-time, and were much older than their fellow students.

For the comparison between the general Swiss population and HP students, data were pooled yielding an initial combined sample size of $n=23,445$. Moreover, we extracted three demographically-stratified samples of female participants aged 21-30 years with secondary $(n=$ $848)$, tertiary $(n=386)$, and secondary or tertiary education $(n=1234)$ from the SHS to match the corresponding female HP students $(n=1501)$ yielding a restricted pooled sample of $n=2349 ; n=1887$; and $n=2735$. The comparison of HP students who were about to complete tertiary education with SHS respondents in the three respective samples served to assess potential education related differences in pain prevalence. More specifically, SHS respondents indicated their education level but we lacked information on whether they were completing a higher level of education at that time, i.e. respondents who completed secondary education may or may not have been studying at the tertiary level at the time the SHS was administered. Consequently, we used the three restricted samples to assess whether HP students' pain prevalence were more similar to SHS respondents who completed tertiary education or to SHS respondents who completed secondary education or were more similar to a mixture of SHS respondents with either completed secondary or tertiary education.

\section{Outcomes: Prevalence of LBP and NP}

Self-reported LBP and NP, the target outcomes of this study, were derived from self-reported data. SHS participants were confronted with a list of health problems, including LBP and NP, and were asked to report for each health problem whether they had experienced it (Question: "I will read out different health problems. Please tell me for each of these health problems whether in the past 4 weeks you have had it"). Responses were captured using a three-point ordinal scale (no, a little bit, strong). Similarly, the Nat-ABBE asked respondents to report health problems (Question: "In the past year, have you had one or more of the following health problems?"); responses were captured using a four-point ordinal scale (no, rarely, occasionally, often). Unfortunately, the SHS wording of the question ("Bitte sagen Sie mir jedes Mal, ob Sie das in den letzten 4 Wochen überhaupt nicht, ein bisschen oder stark gehabt haben.") is not very precise and its closeness to colloquial language makes it difficult to judge whether it referrers to the frequency or intensity of pain. Similarly, the three categories do not allow 
for a final judgment of what respondents had in mind when they answered the SHS question because the categories "a little bit" and "strong" may also refer to either frequency or intensity in many Swiss dialects. In contrast, the Nat-ABBE clearly refers to pain frequency. Despite this ambiguity and the difference in the number of response categories, we feel it is safe to assume that the common category "no" describes absence of pain in general, i.e. frequency and intensity of pain is zero while any other category describes the presence of pain in general. Therefore, we derived a subject-specific binary outcome for LBP and NP (yes/no), indicating the presence or absence of pain. Prevalence of LBP and NP was conceived as the proportion of respondents reporting pain. While the dichotomization of response categories for LBP and NP in our study was primarily driven by the need to make outcomes more comparable across the two surveys, it is also not unusual for prevalence studies of LBP and NP to use dichotomous outcomes [30]. The systematic review of Hoy et al. [31] show that the majority of studies (661 of 893) do not specify the minimum episode duration necessary for inclusion, while one day was the most used when reported. As such, prevalence of LBP and NP used in our study is comparable to other studies. However, our self-reported prevalence of LBP and NP may differ from prevalence estimates in which minimum episode duration was specified [31].

Collapsing of categorical variables, whilst valid, involves loss of information and may lead to reduction in efficiency in the statistical analysis under consideration [32]. Moreover, changing outcome categories can affect the effect estimates as well as the inferences drawn from the data [33, 34]. In order to address the latter issue and justify the dichotomization of our dependent variables, we assessed the association between age, gender, education, and LBP and NP respectively [35]. We compared the results obtained for the dichotomous variables using a logistic model with the results obtained for the original ordered categorical variables using a cumulative odds model (results not shown). The results yielded by the logistic model were confirmed by the alternative cumulative odds model, which incorporated the original three (SHS) and four (Nat-ABBE) ordered categories of LBP and NP, i.e. we found similarity of results regarding the size and statistical significance of effects. Furthermore, collapsing the original dependent variables into two instead of three categories was motivated by the need to derive clearly distinguishable categories from two different scales and simultaneously provide measures of LBP and NP, which achieve the best possible comparability with other studies, i.e. roughly $74 \%$ of the studies considered by Hoy et al. [31] reported prevalence of LBP based on dichotomous outcome measures (presence/absence of LBP).
Prevalence differs substantially according to prevalence period, i.e. point, four-week, yearly or lifetime. In students, yearly prevalence of LBP and NP was assessed (via the Nat-ABBE), while the national population was assessed (via the SHS) based on four-week prevalence. We derived frequency weights based on a well-cited systematic review of LBP, reporting and comparing 145 four-week and 271 yearly prevalence of LBP [31], to estimate comparable four-week prevalence in students. The systematic review found that on average, yearly prevalence was 1.25 times higher than four-week prevalence. Frequency weights were calculated as following:

$$
\begin{aligned}
& \omega_{1}=1.25^{-1} \\
& \omega_{2}=\frac{N-\left(\omega_{1} \cdot n_{1}\right)}{n_{2}} \\
& N=\sum \omega_{i}
\end{aligned}
$$

Where:

$\mathrm{N}$ is to total number of students in the sample

$\mathrm{n}_{1}$ is the number of students with the pain condition

$\mathrm{n}_{2}$ is the number of students without the pain condition

$\omega_{1}$ is the frequency weight for students with the pain condition

$\omega_{2}$ is the frequency weight for students without the pain condition

\section{Frequentist and Bayesian statistical approaches}

Binary regression models were employed to estimate crude and adjusted prevalence. Adjustment comprised age, gender, and education. We used a conventional frequentist statistical approach for the comparison between HP students and the general Swiss population. However, a Bayesian statistical approach was employed for the comparison among HP students because of its flexibility to derive many different models, i.e. dyadic comparisons among the five health professions, from the posterior distribution. The posterior distribution was determined using Markov-Chain-Monte-Carlo (MCMC) sampling. In order to assess convergence, we initially used 4 chains with 4000 iterations and monitored the corresponding trace plots. For the final estimates, a single chain with 20,000 iterations was used. The first 2000 iterations were discarded (burn-in phase). Non-informative priors, i.e. $\mathrm{N}(0,5)$, were used for all parameters in the binary models.

\section{Statistical analysis}

We used R Version 3.4.3 (R Foundation for Statistical Computing, Vienna, Austria), the package 'survey' [36, 37], and Stan [38] for statistical analyses. We reported estimated LBP and NP prevalence with corresponding 95\% confidence intervals $(95 \% \mathrm{CI})$ or $95 \%$ highest posterior 
density intervals (95\% HPDI), respectively. Differences between the national population and students were assessed using design-based F-tests, which take into account the complex survey structure of the SHS [39]. Statistical significance was established at $p<0.05$ [40]. Differences among students were assessed using predicted posterior mean differences in pain prevalence between student groups with corresponding 95\% HPDI.

\section{Results}

\section{Socio-demographic characteristics of respondents}

Sociodemographic and health status characteristics of the initial combined sample are presented in Table 1. Not surprisingly, HP students differed substantially and significantly from the general population with respect to sociodemographics. HP students were younger (age 25.0 \pm 3.9 ) than the general population (age $47.4 \pm 18.8$ ), more likely female $(88.1 \%$ vs $51.0 \%)$, and represented a homogenous group with respect to their highest level of education (100\% secondary education).

Table 1 Socio-demographic characteristics and prevalence of back pain and neck pain in the Swiss Health Survey ${ }^{a}$ and in the survey of final year health professions students

\begin{tabular}{|c|c|c|c|}
\hline Variable & SHS & Nat-ABBE & $\mathrm{P}$ \\
\hline Back pain (\%) & & & 0.000 \\
\hline No & 60.0 & 39.0 & \\
\hline Yes & 40.0 & 61.0 & \\
\hline Neck pain (\%) & & & 0.000 \\
\hline No & 63.6 & 40.2 & \\
\hline Yes & 36.4 & 59.8 & \\
\hline Gender (\%) & & & 0.000 \\
\hline Women & 51.0 & 88.1 & \\
\hline Men & 49.0 & 11.9 & \\
\hline Age group (\%) & & & 0.000 \\
\hline$<21$ & 7.2 & 0.1 & \\
\hline $21-30$ & 15.1 & 94.7 & \\
\hline $31-40$ & 15.8 & 3.5 & \\
\hline $41-50$ & 20.3 & 1.5 & \\
\hline$>50$ & 41.6 & 0.3 & \\
\hline Education (\%) & & & 0.000 \\
\hline Primary & 18.0 & 0.0 & \\
\hline Secondary & 53.4 & 100.0 & \\
\hline Tertiary & 28.6 & 0.0 & \\
\hline Sample size & 21,597 & 1848 & \\
\hline Population size & $6,838,268$ & & \\
\hline
\end{tabular}

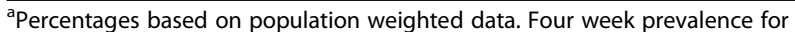
back pain and neck pain. $P$-values from design-based F-test

Source: Swiss Federal Statistical Office, Swiss Health Survey (SHS) 2012. NatABBE coordination group, National Graduate Survey of Health Professionals from Universities of Applied Sciences 2016, 2017 (Nat-ABBE)
Four-week prevalence in health professions' students and in the general population

The crude overall four-week prevalence (mean $(95 \%$ CIs)) for LBP in all HP students was 61.0\% (58.4-63.5) versus $40.0 \%(39.2-40.9)$ in the general Swiss population (Table 1). Similarly, the crude overall prevalence for NP was significantly higher in all HP students $(59.8 \%$ (57.262.3)) than in the general Swiss population (36.4\% (35.6-37.3)). In order to adjust for age, gender, and education, we restricted the HP student sample to women aged 21-30 years (all with completed secondary education) and compared it with three corresponding restricted SHS samples of women in the same age group. The first SHS sample comprised only woman with completed secondary education, the second comprised only woman with completed tertiary education and the third included women who had either completed secondary or tertiary education. These three samples were used to comprehensively reflect SHS cases most likely to match the students. HP students had substantially higher prevalence of LBP and NP as compared to all three restricted SHS samples. Female HP students aged 21-30 years 63.3\% (60.5-66.1)) reported higher LBP than the same-aged Swiss female population with secondary (43.7\% (39.5-47.9)), tertiary (36.6\% (30.8-42.9)), and secondary or tertiary $(41.4 \%(38.0-45.0))$ education. Moreover, female HP students aged 21-30 years reported higher NP (63.2\% (60.4-66.0)) than the same-aged Swiss female population with secondary $(36.6 \%(32.7-40.8))$, tertiary $(35.4 \%(29.6-41.8))$, and secondary or tertiary $(36.2 \%$ (32.9-39.7)) education.

\section{Yearly prevalence and differences of yearly prevalence among HP students}

The adjusted yearly prevalence of LBP (mean $(95 \%$ HPDI)) was $76.4 \%$ (74.4-78.3) in the total sample of HP students (Table 2). We found the highest adjusted yearly prevalence of LBP in students of midwifery $(80.6 \%$ (74.4-86.4)), followed by students of nursing $(77.9 \%$ (75.7-80.1)), and students of occupational therapy $(77.0 \%(71.6-82))$. Students of nutritional sciences had the lowest prevalence (67.0\% (58.7-75.1)). Differences in prevalence were substantial between students of nutritional sciences as compared to students of occupational therapy, midwifery, and nursing (Fig. 1) for which the probability of observing no difference or a negative difference, i.e. a lower prevalence as compared to students of nutritional sciences, was only $0.031,0.005$, and 0.005 , respectively. Likewise, given the data and the model, the probability of observing a lower adjusted yearly prevalence of LBP in students of midwifery as compared to students of physiotherapy was 0.039 .

The overall adjusted yearly prevalence of NP in HP students (Table 3) was $75.0 \%$ (72.8-77.1). Again, the 
Table 2 Yearly prevalence of low back pain in final year health professions students by profession

\begin{tabular}{|c|c|c|c|c|}
\hline Profession & Crude prevalence (\%) & 95\% HPDI & Adjusted prevalence (\%) & 95\% HPDI \\
\hline Occupational Therapy & 77.1 & $70.9-83.3$ & 77.0 & $71.6-82.0$ \\
\hline Nutritional Sciences & 65.9 & $58.3-73.6$ & 67.0 & $58.7-75.1$ \\
\hline Midwifery & 81.1 & $75.0-86.2$ & 80.6 & $74.4-86.4$ \\
\hline Nursing & 77.0 & $74.3-79.6$ & 77.9 & $75.7-80.1$ \\
\hline Physiotherapy & 72.6 & $68.5-76.7$ & 73.9 & $69.7-78.2$ \\
\hline All & 75.6 & $73.6-77.6$ & 76.4 & $74.4-78.3$ \\
\hline
\end{tabular}

Adjusted prevalences: adjusted for age and gender. 95\% HPDI: 95\% highest posterior density interval

Source: Nat-ABBE coordination group, National Graduate Survey of Health Professionals from Universities of Applied Sciences 2016, 2017

prevalence was highest in students of midwifery $(82.3 \%$ (76.1-88.1)). Students of the remaining professions all had very similar adjusted yearly prevalence of NP of roughly $75 \%$. With respect to differences among HP students (Fig. 2), the probability of observing a lower adjusted yearly prevalence of NP in students of midwifery as compared to students of nursing or physiotherapy was 0.006 and 0.036 , respectively.

\section{Discussion}

We examined Swiss Health Survey data from 2012 and data from the National Survey of Final Year HP Students (2016 and 2017 cohorts combined) to estimate the prevalence of LBP and NP specific to Switzerland. Our results revealed worryingly high prevalence for both LBP and NP in final year HP students when compared to the general and demography-stratified Swiss population.
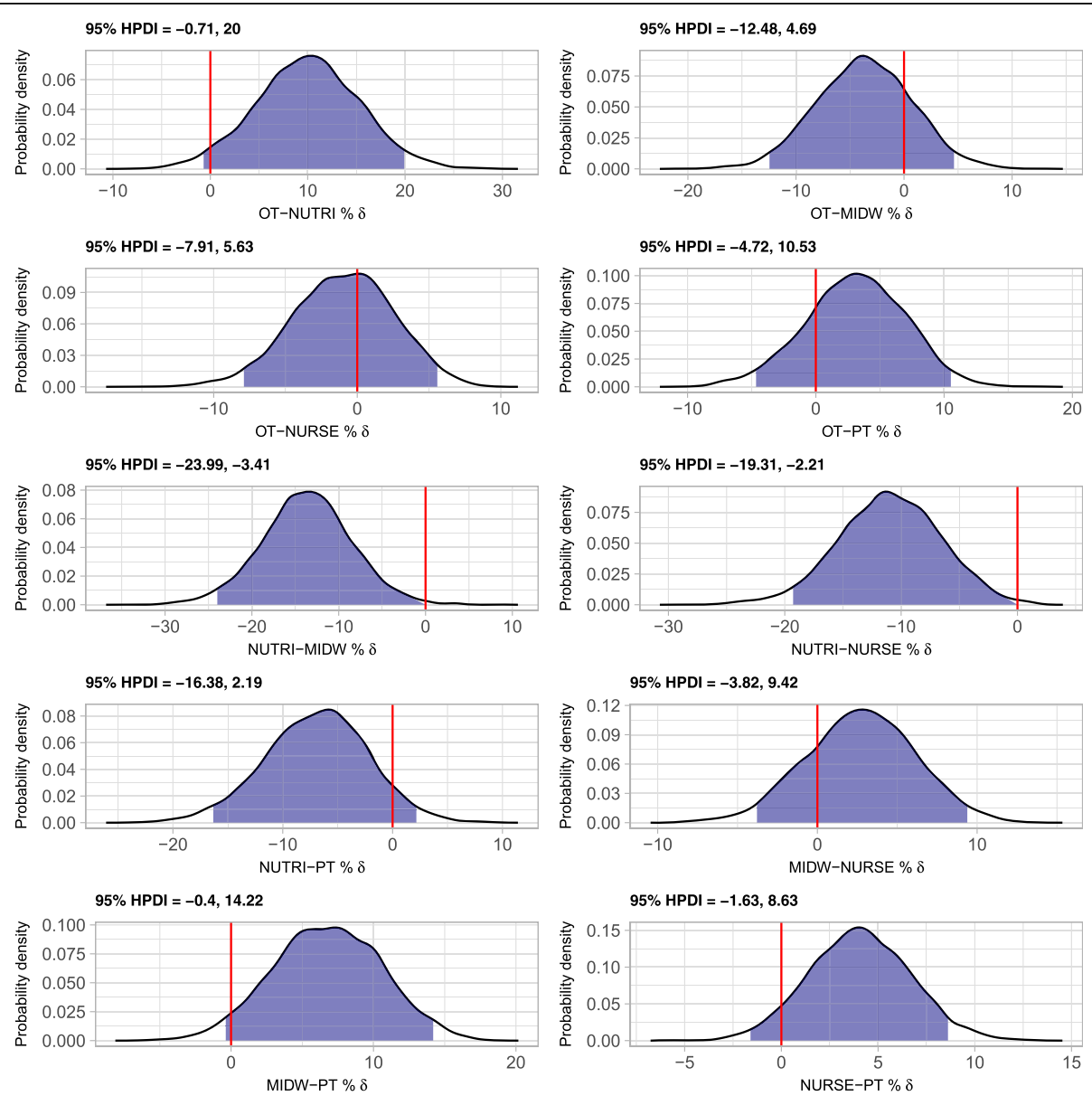

Fig. 1 Probability density of differences in adjusted yearly prevalences of low back pain among health professions' students. 95\% HPDI: 95\% highest posterior density interval. Source: Nat-ABBE coordination group, National Graduate Survey of Health Professionals from Universities of Applied Sciences 2016, 2017 
Table 3 Yearly prevalence of neck pain in final year health professions students by profession

\begin{tabular}{|c|c|c|c|c|}
\hline Profession & Crude prevalence (\%) & 95\% HPDI & Adjusted prevalence (\%) & 95\% HPD \\
\hline Occupational Therapy & 75.3 & $69.7-80.5$ & 75.6 & $69.8-81.0$ \\
\hline Nutritional Sciences & 76.2 & $69.2-83.1$ & 76.4 & $68.6-83.4$ \\
\hline Midwifery & 83.4 & $78.7-87.6$ & 82.3 & $76.1-88.1$ \\
\hline Nursing & 72.4 & $69.6-75.1$ & 73.2 & $70.4-76.1$ \\
\hline Physiotherapy & 72.4 & $68.0-76.6$ & 75.3 & $71.2-79.5$ \\
\hline All & 73.9 & $72.0-76.0$ & 75.0 & $72.8-77.1$ \\
\hline
\end{tabular}

Adjusted prevalences: adjusted for age and gender. 95\% HPDI: 95\% highest posterior density interval

Source: Nat-ABBE coordination group, National Graduate Survey of Health Professionals from Universities of Applied Sciences 2016,2017

These results are particularly concerning for a group yet to embark on their careers in professions that may be deemed more physically hazardous than for many other professions. Beginning professional careers with disabling conditions like LBP and NP may threaten professional longevity and heighten the already projected workforce shortage. While the prevalence shown in the HP students studied are worrying enough, of additional concern is our finding that suggests that midwifery final year students are particularly susceptible to experiencing both conditions. We are unable to support causal relationships due to our study design, but contend that further research is urgently required to explain the high prevalence of LBP and NP in HP students compared to their national peers. Further, we have indicated interprofessional susceptibilities that necessitate further study in order that mitigating management strategies can potentially be introduced into curricula. Further, we suggest that students' physical and mental health be recognized (and measured) as vital in developing competence for clinical practice.

The yearly prevalence for LBP (76\%) and NP (75\%) in final year HP students in our cohort is not only higher than the age, gender, and education-matched respondents to the SHS, but also apparently high when compared to mean values reported for professionals in clinical practice where yearly LBP is around 53\% [26] and NP, 45\% [27]. Further, our rates appear high compared to the literature for other HP students $[20,22,23$, 41-43], and particularly so for the midwifery students in our cohort who describe over $80 \%$ yearly prevalence for both conditions, which even exceeds accepted global lifetime prevalence estimates $[3,4,9,31]$. While we remain cautious in comparing our values to global studies where various factors may differ (e.g. measures, timeframes and definitions), there can be no question our worrying findings warrant further study for explanation. In examining nursing and midwifery students, Williams \& Crawford [44] report a 76\% incidence of back pain, which we speculate may be elevated due to their inclusion of midwifery students who are shown, as one example, to attribute different meanings to varied pain descriptors [45]. In their study examining LBP prevalence in students from eight HPs (including medicine and dentistry but not midwifery), AlShayhan \& Saadeddin [21] report their highest prevalence in dentistry students with 61\%, which crude and adjusted prevalence for each of our professions exceeds (refer to Table 2). The present data-driven cross-sectional study was not designed to explain why this may be the case, but we acknowledge the rationale is multi-factorial and further exploration may best focus on the Swiss context given probable cultural and demographic influences. Furthermore, despite differing crude prevalence across studies, it will be important to understand whether similar patterns for professional susceptibilities exist in other countries [20-22], for example like in our nutritional sciences students where NP may represent more of a problem than LBP.

Not only are HPs affected themselves by the mounting burden of musculoskeletal disorders like LBP and NP they are collectively part of delivering treatment and prevention of such common health problems. While treating the public's LBP and NP may lean more within one professional domain (e.g. physiotherapy) than another (e.g. nursing), it is sound professional practice for any clinician, irrespective of profession, to promote healthy behaviors in their patients/clients. For example, an occupational therapist working to improve a patient's fine-motor hand skills will concurrently optimize the position and posture of the patient's upper quadrant, including the head, neck and upper limb; further, they should be considering optimizing their own physical health in executing the intervention. However, certain professional practice environments (e.g. midwives tasked with delivering a baby within a client's home) may not be easily controlled and therefore less conducive to healthy practice for the HP themselves. In this situation, the HP requires knowledge and awareness to assess the environment with their own health in mind, in addition to that of their patient [41].

Health promotion and prevention is an important part in education and training of the world's HPs. In Switzerland, tertiary HP training programs are based on 

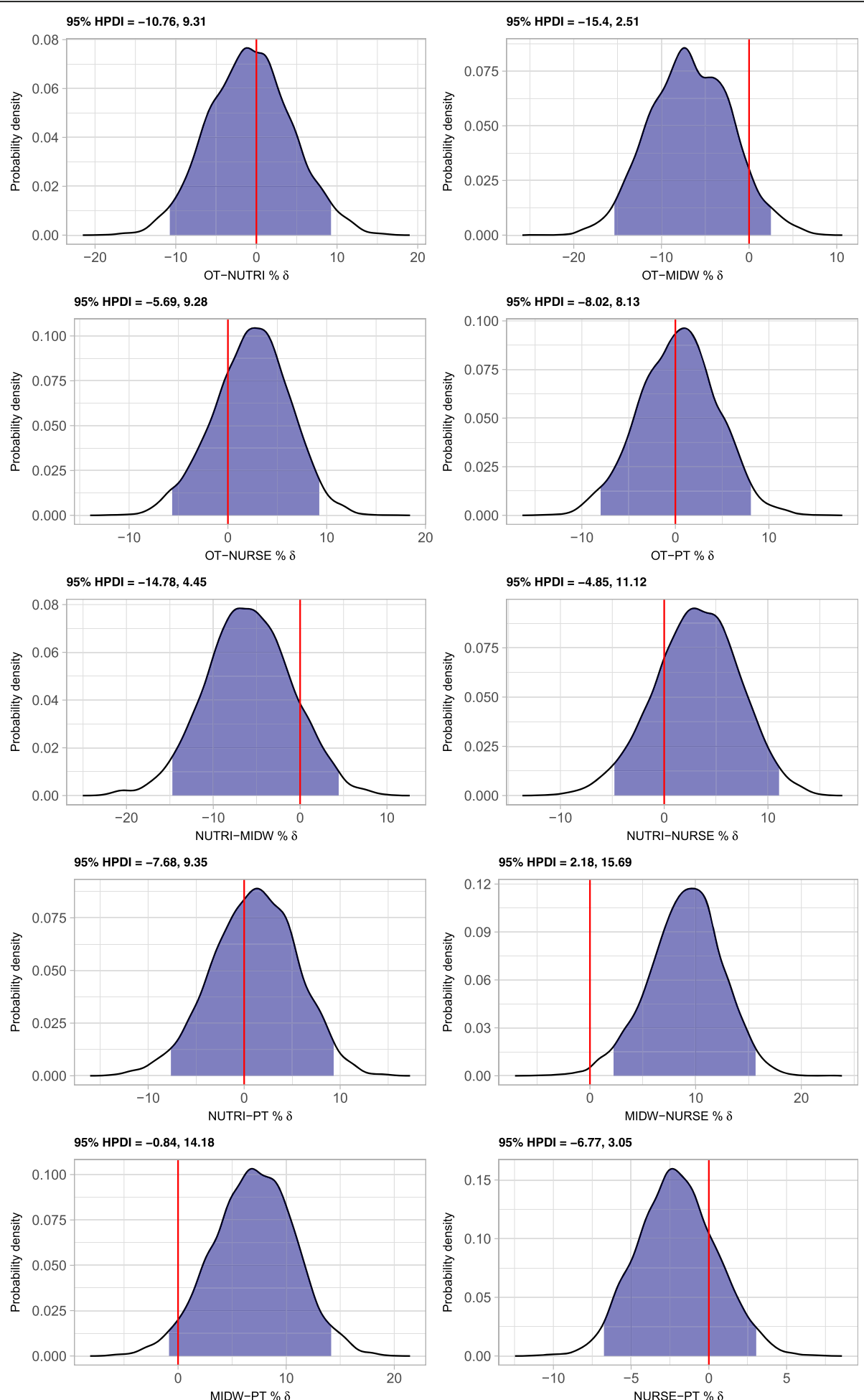

Fig. 2 Probability density of differences in adjusted yearly prevalences of neck pain among health professions' students. 95\% HPDI: 95\% highest posterior density interval. Source: Nat-ABBE coordination group, National Graduate Survey of Health Professionals from Universities of Applied Sciences 2016, 2017 
the CanMEDS Framework that defines seven different roles for HPs [46]. One of these roles is the "Health Advocate", which is defined by the competency to "promote the health of individual patients, communities and populations" [46]. On this basis, we argue that training institutions should invest in inter-professional programs and/or taught curricula across their HPs that increase student and staff knowledge about such common and disabling conditions like LBP or NP. In particular, we contend that being able to identify their own or colleague behaviors that are known to predispose to LBP or NP, and how to avoid or compensate for them may be important in promoting long and enjoyable careers. Understanding HP students' susceptibilities in relation to other professional student groups will be important to establish whether HP students are more attuned to musculoskeletal disorders, potentially based on their education. We consider a multi-professional exploration of student health status to be an important next step in extending our work.

Contrary to global wisdom, our findings indicate that 21-30 year old women with secondary or tertiary-education do not experience more LBP or NP than the general Swiss population (or at least respondents of the SHS). Rationale explaining this finding may be grounded in methodological limitations (described below), but may indicate a public health context unique to Switzerland; this strongly supports further study with targeted parameters relevant to Switzerland. Based on previous work undertaken by our group and others, young adults across Switzerland show wide variation in their health status [47] and appear at risk for declining self-reported health into the future [48]. It is clear from the findings of the present study that future research examining mechanisms that underpin LBP and NP in HP students in Switzerland is warranted, particularly in identifying inter-professional differences and risks that can be modified during the students' formative professional education. As emerging clinicians with limited clinical exposure, HP students have relative inexperience in or awareness of the competencies needed to cope with physically demanding work practices, and may benefit from work-hardening measures that develop physical and manual handling attributes. As part of the wider competency framework study, students in our cohort will be followed at the first year after graduation, which allows for longitudinal examination of LBP and NP prevalence in the context of retention in the workforce. Prevalence of other health parameters surveyed in the NAT-ABBE will be examined in relation to healthcare usage/demand in further study.

While our study has strengths in what we believe to be the first to examine the prevalence of LBP and NP in HP students within a national context, employing a rigorous and contemporary statistical approach, and in revealing professional susceptibilities that warrant further qualitative and quantitative investigation, our findings should be considered in light of the study limitations.

Firstly, the SHS and NAT-ABBE survey were administered in 2012 and 2016/17 respectively. Consequently, period effects, while likely minimal, may bias our results because secular changes like lifestyle and teaching or studying practices between 2012 and 2016/17 could not be accounted for.

Secondly, while employing two Swiss datasets based on self-reported surveys with many similarities and that homogenize the context, the two surveys asked slightly different questions regarding LBP and NP and provided slightly different answer categories. In order to mitigate this problem, we derived dichotomous outcome variables that indicated the presence of absence of pain. However, collapsing response categories leads to a loss of information contained in the data. Moreover, simulation studies showed that collapsing outcome variables might affect the effect estimate as well as the inference being drawn from the data, particularly in a data set of limited size, i.e. less than 200 observations [33]. However, our sensitivity analyses found similarity of results regarding the size and statistical significance of effects yielded by a logistic model and an alternative cumulative odds model, which incorporated the original three (SHS) and four (Nat-ABBE) ordered categories of LBP and NP.

Thirdly, the SHS and NAT-ABBE survey referred to different time-frames, i.e. four-week and yearly prevalence of LBP and NP. In order to compare HP students with the general population, we used weights to convert yearly prevalence to four-week prevalence. While we admit that this is only a crude approximation of the "true" four-week prevalence, our sensitivity analysis showed that our results were still supported when weights were reduced by a substantial $25 \%$ percent.

Fourthly, several studies suggest that cultural and social factors affect the meaning of pain not only for patients but as well for health professionals [49-52]. Since HP students are socialized and educated within the cultural domain of the healthcare system, they may have adopted a different concept and understanding of pain compared to the general population. However, our study did not assess whether and to what degree different concepts of pain were associated with the prevalence of NP and LBP and future studies should address this issue.

\section{Conclusions}

Swiss final year HP students when compared with the general and demography-stratified national population reported considerably higher LBP and NP. This worrying finding suggests high risk for LBP and NP in students of 
the clinical professions studied, and where midwifery may be particularly susceptible. Further study is urgently needed to explain these results and in order to institute mitigating strategies to improve student health outcomes. We contend that tertiary institutions are responsible for their students' health in addition to developing student's professional skills and competence in commencing clinical careers. Tertiary institutions should therefore provide education, awareness, and experiences that promote retention in the workforce, which we clearly show that musculoskeletal disorders may threaten. Whether health professions students represent a unique risk for these conditions should be examined against students studying other professions.

\section{Abbreviations}

95\% Cl: 95\% confidence intervals; 95\% HPDI: 95\% highest posterior density interval; LBP: Low back pain; Nat-ABBE: National Graduate Survey of Health Professionals from Universities of Applied Sciences; NP: Neck pain; SFSO: Swiss Federal Statistical Office; SHS: Swiss Health Survey

\section{Acknowledgements}

Authors would like to thank participating Swiss Universities of Applied Sciences, and namely their representatives in the Nat-ABBE project group for their collaboration in collecting and sharing the data used in this paper: Godela Dönnges (Zürcher Hochschule für Angewandte Wissenschaften ZHAW), Andrea Mahlstein (Berner Fachhochschule BFH), Heidi Zeller (Fachhochschule St. Gallen), Iren Bischofberger (Kalaidos Fachhochschule), Luca Scascighini (Scuola universitaria professionale della Svizzera italiana SUPSI), and Blaise Guinchard (Haute Ecole Spécialisée de la Suisse occidentale; HES-SO).

\section{Funding}

Not applicable.

\section{Availability of data and materials}

Data of the Swiss Health Survey(s) is publicly available and can be obtained from the Swiss Federal Statistical Office. Nat-ABBE data is publicly available and can be obtained on request from Thomas Bucher as data custodian, and after agreement from representatives of the participating universities.

\section{Authors' contributions}

RJC and TV conceived and designed the study. TB collected and consolidated HP students' data. TV undertook statistical analyses. RJC, TV, RS, and TB contributed to design, data analysis and interpretation, and manuscript development. All authors: made substantial contributions to the analysis and interpretation of the data; were involved in drafting the manuscript and revising it critically for important intellectual content; and gave final approval of the version to be published. All authors are accountable for all aspects of the work in ensuring that questions related to the accuracy or integrity of any part of the work are appropriately investigated and resolved.

\section{Ethics approval and consent to participate}

Data managed and obtained under the regulation of the Federal Statistics Act (FSA) of 1992. Secondary use of the SHS data was approved by the Swiss Federal Statistical Office (contract number 160512) and secondary use of the Nat-ABBE was approved by the board of Nat-ABBE data management directors from all participating universities.

\section{Consent for publication}

Not applicable.

\section{Competing interests}

The authors declare that they have no competing interests.

\section{Publisher's Note}

Springer Nature remains neutral with regard to jurisdictional claims in published maps and institutional affiliations.

\section{Author details}

${ }^{1}$ Faculty of Health Professions, Curtin University, Perth, Australia. ${ }^{2}$ Institute for Health Sciences, Zurich University of Applied Sciences, Winterthur,

Switzerland. ${ }^{3}$ Specialist Unit for Quality Management and Evaluation, Zurich University of Applied Sciences, Winterthur, Switzerland.

Received: 16 April 2018 Accepted: 10 October 2018

Published online: 19 October 2018

\section{References}

1. GBD 2013 Mortality and Causes of Death Collaborators. Global, regional, and national age-sex specific all-cause and cause-specific mortality for 240 causes of death, 1990-2013: a systematic analysis for the Global Burden of Disease Study 2013. Lancet. 2015;385(9963):117-71.

2. Buchbinder R, Blyth FM, March LM, Brooks P, Woolf AD, Hoy DG. Placing the global burden of low back pain in context. Best Pract Res Clin Rheumatol. 2013;27(5):575-89.

3. Hoy DG, Smith E, Cross M, Sanchez-Riera L, Blyth FM, Buchbinder R, Woolf $A D$, Driscoll T, Brooks P, March LM. Reflecting on the global burden of musculoskeletal conditions: lessons learnt from the global burden of disease 2010 study and the next steps forward. Ann Rheum Dis. 2015;74(1): 4-7.

4. Hoy D, March L, Woolf A, Blyth F, Brooks P, Smith E, Vos T, Barendregt J, Blore J, Murray $C$, et al. The global burden of neck pain: estimates from the global burden of disease 2010 study. Ann Rheum Dis. 2014;73(7):1309-15.

5. Angst F, Angst J, Ajdacic-Gross V, Aeschlimann A, Rossler W. Epidemiology of Back pain in young and middle-aged adults: a longitudinal population cohort survey from age 27-50 years. Psychosomatics. 2017;58(6):604-13.

6. Dieleman JL, Baral R, Birger M, Bui AL, Bulchis A, Chapin A, Hamavid H, Horst C, Johnson EK, Joseph J, et al. US spending on personal health care and public health, 1996-2013. Jama. 2016;316(24):2627-46.

7. Suzman R, Beard JR, Boerma T, Chatterji S. Health in an ageing world--what do we know? Lancet. 2015;385(9967):484-6.

8. Bloom DE, Chatterji S, Kowal P, Lloyd-Sherlock P, McKee M, Rechel B, Rosenberg L, Smith JP. Macroeconomic implications of population ageing and selected policy responses. Lancet. 2015;385(9968):649-57.

9. Hoy D, March L, Brooks P, Blyth F, Woolf A, Bain C, Williams G, Smith E, Vos $T$, Barendregt J, et al. The global burden of low back pain: estimates from the global burden of disease 2010 study. Ann Rheum Dis. 2014;73(6):968-74.

10. Ivanova Jl, Birnbaum HG, Schiller M, Kantor E, Johnstone BM, Swindle RW. Real-world practice patterns, health-care utilization, and costs in patients with low back pain: the long road to guideline-concordant care. Spine J. 2011;11(7):622-32.

11. Suman A, Bostick GP, Schopflocher D, Russell AS, Ferrari R, Battie MC, Hu R, Buchbinder R, Gross DP. Long-term evaluation of a Canadian back pain mass media campaign. Eur Spine J. 2017;26(9):2467-74.

12. Traeger AC, Buchbinder R, Harris IA, Clavisi OM, Maher CG. Avoid routinely prescribing medicines for non-specific low back pain. Br J Sports Med. 2018. https://doi.org/10.1136/bjsports-2017-098614.

13. Hoy D, Brooks P, Blyth F, Buchbinder R. The epidemiology of low back pain. Best Pract Res Clin Rheumatol. 2010;24(6):769-81.

14. Hoy DG, Protani M, De R, Buchbinder R. The epidemiology of neck pain. Best Pract Res Clin Rheumatol. 2010;24(6):783-92.

15. Haldeman S, Carroll L, Cassidy JD, Schubert J, Nygren A. The bone and joint decade 2000-2010 task force on neck pain and its associated disorders: executive summary. Spine. 2008;33(4 Suppl):S5-7.

16. Wieser S, Horisberger B, Schmidhauser S, Eisenring C, Brugger U, Ruckstuhl A, Dietrich J, Mannion AF, Elfering A, Tamcan O, et al. Cost of low back pain in Switzerland in 2005. Eur J Health Econ. 2011;12(5):455-67.

17. Grant VJ, Robinson E, Muir P. Sex ratios in healthcare occupations: population based study. BMJ (Clinical research ed). 2004;328(7432):141-2.

18. World Health Organization. Working for health and growth: Investing in the health workforce. Geneva: World Health Organization; 2016.

19. Zurich University of Applied Sciences School of Health Professions: Bachelor degree programmes [https://www.zhaw.ch/en/health/study/bachelordegree-programmes/]. Accessed 20 May 2018. 
20. Almhdawi KA, Mathiowetz V, Al-Hourani Z, Khader Y, Kanaan SF, Alhasan M. Musculoskeletal pain symptoms among allied health professions' students: prevalence rates and associated factors. J Back Musculoskelet Rehabil. 2017; 30(6):1291-301.

21. AlShayhan FA, Saadeddin M. Prevalence of low back pain among health sciences students. Eur J Orthop Surg Traumatol. 2018;28(2):165-70.

22. Falavigna A, Teles AR, Mazzocchin T, de Braga GL, Kleber FD, Barreto F, Santin JT, Barazzetti D, Lazzaretti L, Steiner B, et al. Increased prevalence of low back pain among physiotherapy students compared to medical students. Eur Spine J. 2011;20(3):500-5.

23. Leggat PA, Smith DR, Clark MJ. Prevalence and correlates of low back pain among occupational therapy students in northern Queensland. Can J Occup Ther. 2008;75(1):35-41.

24. Lovgren M, Gustavsson P, Melin B, Rudman A. Neck/shoulder and back pain in new graduate nurses: a growth mixture modeling analysis. Int J Nurs Stud. 2014;51(4):625-39.

25. Vijay S, Ide M. Musculoskeletal neck and back pain in undergraduate dental students at a UK dental school - a cross-sectional study. Br Dent J. 2016; 221(5):241-5.

26. Ellapen T, Narsigan S. Work related musculoskeletal disorders among nurses: systematic review. J Ergonomics. 2014:S4:S4-003.

27. Long MH, Bogossian FE, Johnston V. The prevalence of work-related neck, shoulder, and upper back musculoskeletal disorders among midwives, nurses, and physicians: a systematic review. Workplace Health Saf. 2013; 61(5):223-9 quiz 230.

28. World Health Organization. Framing the health workforce agenda for the Sustainable Development Goals: biennium report 2016-2017: WHO health workforce. Geneva: World Health Organization; 2017.

29. Dolder P, Grüning A. Nationaler Versorgungsbericht für die Gesundheitsberufe 2016. Bern: Schweizerische Konferenez der kantonalen Gesundheitsdirektorinnen und -direktoren (GDK) und Nationale Dachorganisation der Arbeitswelt Gesundheit (OdASanté); 2015.

30. Dionne CE, Dunn KM, Croft PR, Nachemson AL, Buchbinder R, Walker BF, Wyatt M, Cassidy JD, Rossignol M, Leboeuf-Yde C, et al. A consensus approach toward the standardization of back pain definitions for use in prevalence studies. Spine. 2008;33(1):95-103.

31. Hoy D, Bain C, Williams G, March L, Brooks P, Blyth F, Woolf A, Vos T, Buchbinder R. A systematic review of the global prevalence of low back pain. Arthritis Rheum. 2012;64(6):2028-37.

32. McCullagh P. Regression models for ordinal data (with discussion). JRoyal Statistcal Society Series B (Methodological). 1980;42(2):109-42.

33. Strömberg U. Collapsing ordered outcome categories: a note of concern. Am J Epidemiol. 1996;144(4):421-4.

34. Scott SC, Goldberg MS, Mayo NE. Statistical assessment of ordinal outcomes in comparative studies. J Clin Epidemiol. 1997;50(1):45-55.

35. Manor O, Matthews S, Power C. Dichotomous or categorical response? Analysing self-rated health and lifetime social class. Int J od Epidemiology. 2000;29:149-57.

36. Lumley T. 'survey': Analysis of Complex Survey Samples. In: vol. R package version 3.32; 2017

37. Lumley T. Analysis of complex survey samples. J Stat Softw. 2004;9(1):1-19.

38. Carpenter B, Gelman A, Hoffmann MD, Lee D, Goodrich B, Betancourt M, Brubaker M, Guo J, Li P, Riddell A. Stan: a probabilistic programming language. J Stat Softw. 2017;76. https://doi.org/10.18637/jss.v076.i01.

39. Rao JNK, Scott AJ. On chi-squared tests for multiway contingency tables with cell proportions estimated from survey data. Ann Stat. 1984;12(1):46-60.

40. Fisher RA. Statistical methods for research workers. Edinburgh: Oliver and Boyd; 1925.

41. Menzel N, Feng D, Doolen J. Low Back pain in student nurses: literature review and prospective cohort study. Int J Nurs Educ Scholarsh. 2016;13. https://doi.org/10.1515/ijnes-2015-0057.

42. Mitchell $T$, O'Sullivan PB, Burnett AF, Straker $L$, Rudd C. Low back pain characteristics from undergraduate student to working nurse in Australia: a cross-sectional survey. Int J Nurs Stud. 2008;45(11):1636-44

43. Nyland LJ, Grimmer KA. Is undergraduate physiotherapy study a risk factor for low back pain? A prevalence study of LBP in physiotherapy students. BMC Musculoskelet Disord. 2003;4:22.

44. Williams A, Crawford K. Self-medication practices among undergraduate nursing and midwifery students in Australia: a cross-sectional study. Contemp Nurse. 2016;52(4):410-20.

45. Bergh $\mathrm{H}$, Ek K, Martensson LB. Midwifery students attribute different quantitative meanings to hurt, ache and pain: a cross-sectional survey. Women Birth. 2013;26(2):143-6.
46. Frank JR, Danoff D. The CanMEDS initiative: implementing an outcomes-based framework of physician competencies. Med Teacher. 2007;29(7):642-7.

47. Abel T, Hofmann K, Schori D. Social and regional variations in health status and health behaviours among Swiss young adults. Swiss Med Wkly. 2013; 143:w13901.

48. Volken T, Wieber F, Ruesch P, Huber M, Crawford RJ. Temporal change to self-rated health in the Swiss population from 1997 to 2012: the roles of age, gender, and education. Public Health. 2017;150:152-65.

49. Nencini A, Sarrica M, Cancian R, Contarello A. Pain as social representation: a study with Italian health professionals involved in the 'Hospital and district without Pain' project. Health Promot Int. 2015;30(4):919-28.

50. Pillay T, van Zyl HA, Blackbeard D. Chronic pain perception and cultural experience. Procedia - Social and Behavioral Sciences. 2014;113:151-60.

51. Peacock S, Patel S. Cultural influences on pain. Reviews in pain. 2008;1 (2):6-9.

52. Arntz A, Claassens L. The meaning of pain influences its experienced intensity. Pain. 2004;109(1-2):20-5.

\section{Ready to submit your research? Choose BMC and benefit from:}

- fast, convenient online submission

- thorough peer review by experienced researchers in your field

- rapid publication on acceptance

- support for research data, including large and complex data types

- gold Open Access which fosters wider collaboration and increased citations

- maximum visibility for your research: over $100 \mathrm{M}$ website views per year

At BMC, research is always in progress.

Learn more biomedcentral.com/submissions 